\title{
FTIR spectral analysis of bituminous binders: reproducibility and impact of ageing temperature
}

\author{
B. Hofko - L. Porot • A. Falchetto Cannone - L. Poulikakos • L. Huber • \\ X. Lu $\cdot$ K. Mollenhauer $\cdot$ H. Grothe $\mathbb{D}$
}

Received: 1 August 2017/Accepted: 28 February 2018/Published online: 8 March 2018

(C) The Author(s) 2018. This article is an open access publication

\begin{abstract}
This RILEM round robin study with nine participating laboratories investigated bitumen ageing, its effect on chemical properties and its reproducibility. The impact of temperature used for shortterm (RTFOT) binder ageing on the combined shortand long-term (PAV) aged samples was investigated; thereby the effect of reduced mixing temperature such as those relevant for warm mix asphalt technologies on
\end{abstract}

RILEM TC 252 and reviewed and approved by all members of the TC 252

TC Membership:

Chair: Niki Kringos.

Secretary: Lily Poulikakos.

TC Members: Prof. Hussain U. Bahia, Mr. Francisco José Barcelo Martinez, MSc. Jeroen Besamusca, Dr Emmanuel Chailleux, Prof. Hervé Di Benedetto, Dr. Augusto Falchetto Cannone, Dr. Hartmut Fischer, Dr. James Grenfell, Prof. Dr. Hinrich Grothe, Dr. Bernhard Hofko, Ms Greet Leegwater, Dr. Liliane HUBER, Dr. Xiaohu Lu, Dr. Konrad Mollenhauer, Prof. Dr. Uwe Muehlich, Prof. Dr. Manfred N. Partl, Dr. Laurent Porot, Mr. Tom A. Scarpas, Dr Hilde Soenen, Dr. Lucia Tsantilis, Dr. Yuqing Zhang.

B. Hofko $(\bowtie) \cdot$ H. Grothe

Technische Universität Wien, Vienna, Austria

e-mail: bernhard.hofko@tuwien.ac.at

L. Porot

Kraton Chemical B.V., Amsterdam, The Netherlands

A. Falchetto Cannone

Technische Universitaet Braunschweig, Braunschweig, Germany long term ageing was examined. Four 70/100 penetration graded bituminous binders from different sources were selected. In addition to the standard RTFOT temperature of $163{ }^{\circ} \mathrm{C}$, two additional temperatures, 143 and $123{ }^{\circ} \mathrm{C}$ were used. The Fourier transform infrared spectroscopy (FTIR) analysis was carried out using an integration method which considers the area below the absorbance spectrum around a band maximum using baseline and tangential approaches. A statistical investigation into the reproducibility of FTIR spectra analysis based on the accumulated data was done. To assess the reproducibility, the coefficient of variation $(\mathrm{CV})$ was taken as a benchmark parameter. Carbonyl and sulfoxide indices were calculated using different baseline correction methods and tangential and baseline integration, respectively. It was shown that the tangential method was not influenced by the applied baseline correction. However, in all considered cases, the tangential method led to significantly worse reproducibility (CVs ranging from 20 to $120 \%$ ) compared

\author{
L. Poulikakos \\ Empa, Swiss Federal Laboratories for Materials Science \\ and Technology, Dubendorf, Switzerland \\ L. Huber \\ IMP Bautest AG, Oberbuchsiten, Switzerland \\ X. Lu \\ Nynas AB, Stockholm, Sweden
}


to the baseline method. The sulfoxide indices calculated by both methods were not affected by the baseline correction method used. Impacts of changes in the short-term ageing temperature on short- or longterm aged samples could not be found whereas differences between different binder sources could be detected. RTFOT temperature and therefore mix production temperature had a stronger impact on the formation of sulfoxide structures than for carbonyl structures. The findings from this study show the most reproducible of all considered methods when more than one laboratory is providing FTIR data.

Keywords FTIR - Bitumen - Asphalt - Oxidation · Ageing $\cdot$ Reproducibility $\cdot$ RTFOT $\cdot$ PAV

\section{Introduction}

Bituminous binders used extensively in asphalt mixes for construction of pavements are mainly obtained from the refining of crude oil through distillation processes. This material is well-considered as a complex organic matter since it is composed of a large number of hydrocarbons and other elements (mainly $\mathrm{O}, \mathrm{N}, \mathrm{S}$, and traces of metals). The physical properties of asphalt binders, including its response to applied stress or strain, are highly temperature, time, and loading rate dependent and are thus classified as a viscoelastic substance for mechanistic analysis [1-3]. From a chemical point of view, bituminous binders are sensitive to environmental non-load related actions, mostly oxidative ageing $[4,5]$. The oxidative ageing of bitumen occurs in two main stages: in short-term during asphalt mix production while mixing binder and aggregates at elevated temperature (between 140 and $200{ }^{\circ} \mathrm{C}$ ), transport and compaction; and in longterm when the asphalt mix is in service over time in a pavement structure. Although the mechanism of ageing of bituminous binders is very complex, its consequences on physical and macro-mechanical properties are well-understood. Under sufficient supply of reactive oxygen species in the atmosphere, the

K. Mollenhauer

University of Kassel, Kassel, Germany oxidative ageing reaction causes the bituminous binder to become stiffer, less temperature susceptible and more brittle, mostly agreed to be upon increasing association among polar components of the binder. While the rheological behavior of bitumen and its change with ageing on the macro-level has been extensively studied in the last decades [6-13] and sophisticated models have been developed to describe the complex behavior of this material [14-20], the chemical composition of bitumen, its changes with ageing, and in-depth analysis of its impact on the mechanical behavior, is still subject to studying [21-28] and intrigue many researchers in chemistry and civil materials engineering fields.

Several methods have been used to analyze the chemistry of bituminous binders including the Corbett chromatography, Gas or Gel Permeation Chromatography and Fourier Transform Infrared Spectroscopy (FTIR). Amongst these techniques, FTIR is a popular method to investigate changes in the chemical composition due to oxidative ageing [29-39]. In general, the objective of absorption spectroscopy, as in FTIR, is to gain information on how much a given sample absorbs light (i.e., infrared radiation) at a certain wavelength range. For mid FTIR, this wavelength usually ranges from 2.5 to $25 \mu \mathrm{m}$, which corresponds to wavenumbers from 4000 to $400 \mathrm{~cm}^{-1}$. FTIR makes use of the fact that bonds in molecules absorb infrared light at frequencies that are characteristic for their vibrations, i.e. resonant frequencies. The selection rules for those IR active bands depend inherently on the symmetry of the molecules or molecular groups and are thus related also to the structure of the material. Different groups of molecular bonds can be unambiguously distinguished at different, well-defined wavelengths of an absorbance spectrum by characteristic bands (local maxima in the spectrum) [40]. For bituminous binders, especially those structures associated with oxidative ageing, i.e. uptake of oxygen, have been in the focus of attention in research: (1) The carbonyl functional group has been used to characterize the level of bitumen oxidation and a linear relation between the increase of the $\log$ of viscosity and the increase in carbonyl concentration during bitumen ageing procedures has been established [41]. (2) The sulfoxide group is often produced in higher amounts than carbonyl, mainly in bitumen containing high sulfur content. Changes in these chemical groups can then be correlated to changes in 
the rheological properties and allow for a better understanding of chemo-mechanical coupling [42].

Of particular interest is the repeatability and reproducibility of such results. A recent round robin test was performed between seven laboratories using RTFOT aged binders [43]. This study compared Attenuated Total Reflectance (ATR) and transmission spectroscopy and recommends working with transmission spectroscopy since it produces more repeatable results. However, the sample size was very limited ( $n=5$ for transmission and $n=4$ for ATR). Thus, the conclusions of this study are seen as preliminary. Another recent study looked into the repeatability of different approaches to analyze ATR FTIR spectra from bituminous binders [44] in various ageing states from unaged to RTFOT and PAV aged. It was found that integration based methods show a repeatability in terms of coefficient of variation (CV) of 3.0-5.5\%.

However, an investigation into the reproducibility of FTIR spectral analysis on bituminous binders with a larger sample size is still missing. Information on reproducibility of FTIR analysis and how to optimize it would potentially improve future research in this field, since it would make results produced by different teams comparable. The results presented here are part of the work of RILEM technical committee chemo mechanical characterization of bituminous materials 252 CMB.

\subsection{Objectives and methodology}

The central goal of this RILEM round robin testing program is to increase the knowledge on bitumen ageing and its effect on mechanical and chemical properties of the material. The impact of a variation of the temperature $\left(123,143,163{ }^{\circ} \mathrm{C}\right)$ used for short-term (RTFOT) binder ageing on the behavior of short- and long-term (PAV) aged samples is in the center of attention. The motivation is to examine the effect of reduced mixing temperature such as in warm mix asphalt technologies on long term ageing. In addition, correlations between mechanical and chemical properties are investigated to better understand the impact of ageing on changes in the chemical composition, and how this affects the observed mechanical behavior.

This paper looks into one part of this extensive study, which is the FTIR analysis of binder samples in different ageing states. The objective is to gather more information on the quality of spectral data obtained from laboratories working with different FTIR setups. In addition, different approaches on how to improve the reproducibility of data received from different participants by state-of-the art manipulations of the individual spectra were investigated. The approach that provided best reproducibility for well-defined indices that describe the state of oxidative ageing was further employed to analyze the impact of short-term ageing temperature on the oxidative ageing of shortand long-term aged binder samples.

\subsection{Participating laboratories}

The following group of nine laboratories from seven countries, representing academia and industry, participated in the round robin tests:

- Braunschweig University of Technology \& University of Kassel, Germany

- Empa, Switzerland

- Michigan Technological University, USA

- Kraton Chemical

- Vienna University of Technology, Austria

- Q8, The Netherlands

- IMP, Switzerland

- Nynas, Sweden

- Repsol, Spain

\section{Materials and methods}

Four 70/100 penetration graded bituminous binders [45] from different crude sources were used in this study and identified as B501, B502, B503 and B504. In addition, suffixes "A", "B_Temp" and "C_Temp" were used to give information on the state of ageing: unaged, RTFOT [46] and PAV [47] and on the RTFOT ageing temperature $\left(123,143\right.$ and $\left.163{ }^{\circ} \mathrm{C}\right)$ as exemplified below:

- Unaged binder: A (e.g. B501A)

- RTFOT-aged binder: B_Temp (e.g. B501B_163 for sample B501 aged in the RTFOT at $163{ }^{\circ} \mathrm{C}$ )

- PAV-aged binder: C_Temp (e.g. B501C_143 for sample B501 aged in the RTFOT at $143{ }^{\circ} \mathrm{C}$ and subsequently in the PAV)

Table 1 provides basic characteristics of the four binder samples according to European Standards [48, 49] and US Performance Grade System [50]. 
Table 1 Characteristics of bitumen samples

\begin{tabular}{lllr}
\hline Sample & Penetration at $25^{\circ} \mathrm{C}(1 / 10 \mathrm{~mm})$ & Softening point $\left({ }^{\circ} \mathrm{C}\right)$ & PG \\
\hline B501 & 77 & 46.2 & $70-22$ \\
B502 & 77 & 47.1 & $64-22$ \\
B503 & 79 & 47.5 & $64-22$ \\
B504 & 84 & 47.3 & $64-22$ \\
\hline
\end{tabular}

Table 2 FTIR test program

\begin{tabular}{|c|c|c|c|c|c|c|c|c|c|c|c|c|c|c|c|}
\hline B501 & A & B_123 & B_143 & B_163 & C_123 & C_143 & C_163 & B502 & A & B_123 & B_143 & B_163 & C_123 & C_143 & C_163 \\
\hline Lab 1 & $X$ & & $\mathrm{X}$ & $\mathrm{X}$ & & X & $X$ & Lab 1 & X & & $X$ & $\mathrm{X}$ & & X & $X$ \\
\hline Lab 2 & $X$ & $X$ & & $\mathrm{X}$ & $\mathrm{X}$ & & $X$ & Lab 2 & $X$ & $\mathrm{X}$ & & $\mathrm{X}$ & $\mathrm{X}$ & & $X$ \\
\hline Lab 3 & & & & & & & & Lab 3 & $\mathrm{X}$ & $\mathrm{X}$ & & $\mathrm{X}$ & $\mathrm{X}$ & & $\mathrm{X}$ \\
\hline Lab 4 & $X$ & $X$ & X & & $\mathrm{X}$ & X & & Lab 4 & & & & & & & \\
\hline Lab 5 & $\mathrm{X}$ & $X$ & & $\mathrm{X}$ & $\mathrm{X}$ & & $X$ & Lab 5 & & & & & & & \\
\hline Lab 6 & $X$ & & & $\mathrm{X}$ & & & $X$ & Lab 6 & $\mathrm{X}$ & & & $\mathrm{X}$ & & & $\mathrm{X}$ \\
\hline Lab 7 & $\mathrm{X}$ & $X$ & $X$ & $\mathrm{X}$ & $\mathrm{X}$ & $\mathrm{X}$ & $X$ & Lab 7 & $\mathrm{X}$ & $\mathrm{X}$ & $X$ & & $\mathrm{X}$ & $X$ & \\
\hline Lab 8 & $\mathrm{X}$ & $\mathrm{X}$ & $\mathrm{X}$ & $\mathrm{X}$ & $\mathrm{X}$ & $\mathrm{X}$ & $\mathrm{X}$ & Lab 8 & $\mathrm{X}$ & $\mathrm{X}$ & & $\mathrm{X}$ & $\mathrm{X}$ & $\mathrm{X}$ & $\mathrm{X}$ \\
\hline Lab 9 & $X$ & $X$ & & $\mathrm{X}$ & $\mathrm{X}$ & & $X$ & Lab 9 & $\mathrm{X}$ & $\mathrm{X}$ & & $\mathrm{X}$ & $\mathrm{X}$ & & $\mathrm{X}$ \\
\hline B503 & A & B_123 & B_143 & B_163 & C_123 & C_143 & C_163 & B504 & A & B_123 & B_143 & B_163 & C_123 & C_143 & C_163 \\
\hline Lab 1 & $X$ & & $\mathrm{X}$ & $\mathrm{X}$ & & $\mathrm{X}$ & $\mathrm{X}$ & Lab 1 & $\mathrm{X}$ & & $X$ & $\mathrm{X}$ & & $\mathrm{X}$ & $X$ \\
\hline Lab 2 & $X$ & $X$ & & $X$ & $\mathrm{X}$ & & $X$ & Lab 2 & $X$ & $\mathrm{X}$ & & $\mathrm{X}$ & $\mathrm{X}$ & & $\mathrm{X}$ \\
\hline Lab 3 & & & & & & & & Lab 3 & $X$ & $\mathrm{X}$ & & $\mathrm{X}$ & $\mathrm{X}$ & & $X$ \\
\hline Lab 4 & & & & & & & & Lab 4 & $\mathrm{X}$ & $\mathrm{X}$ & X & & $\mathrm{X}$ & X & \\
\hline Lab 5 & & & & & & & & Lab 5 & $\mathrm{X}$ & $\mathrm{X}$ & & $\mathrm{X}$ & $\mathrm{X}$ & & $X$ \\
\hline Lab 6 & $\mathrm{X}$ & & & $\mathrm{X}$ & & & $X$ & Lab 6 & $X$ & & & $\mathrm{X}$ & & & $\mathrm{X}$ \\
\hline Lab 7 & $\mathrm{X}$ & $X$ & $\mathrm{X}$ & & $\mathrm{X}$ & $\mathrm{X}$ & & Lab 7 & $X$ & $\mathrm{X}$ & $X$ & & $\mathrm{X}$ & $\mathrm{X}$ & \\
\hline Lab 8 & $\mathrm{X}$ & $X$ & $\mathrm{X}$ & $\mathrm{X}$ & $\mathrm{X}$ & $\mathrm{X}$ & & Lab 8 & $X$ & $\mathrm{X}$ & $X$ & $\mathrm{X}$ & $\mathrm{X}$ & $\mathrm{X}$ & $\mathrm{X}$ \\
\hline Lab 9 & $\mathrm{X}$ & $\mathrm{X}$ & & $\mathrm{X}$ & $\mathrm{X}$ & & $\mathrm{X}$ & Lab 9 & $\mathrm{X}$ & $\mathrm{X}$ & & $\mathrm{X}$ & $\mathrm{X}$ & & $X$ \\
\hline
\end{tabular}

The values reported in the table were obtained from Laboratory 8.

Table 2 shows an overview of the test program run using the FTIR. The table allocates which laboratory carried out FTIR on which samples for all four binders. In addition, the last row in each table shows how many spectra are available for which sample.

\subsection{Laboratory ageing}

The entire set of binders was short- and long-term aged. Short-term ageing was performed according to the RTFOT method [46] with a duration of $75 \mathrm{~min}$. In addition to the standard RTFOT temperature of $163{ }^{\circ} \mathrm{C}$, two additional temperatures, 143 and
$123{ }^{\circ} \mathrm{C}$, were used to evaluate the effect of temperature on the ageing process. The choice for the reduced temperatures was based on warm mix asphalt technologies. Long-term ageing was conducted using the PAV device [47]. It was carried out after RTFOT at a temperature of $100{ }^{\circ} \mathrm{C}$ and an air pressure of $2.1 \mathrm{MPa}$ for $20 \mathrm{~h}$.

Each participant received a batch of unaged bitumen samples and carried out RTFOT and PAV ageing in their own laboratories.

\subsection{Sample handling}

Detailed instructions on how exactly to handle the different ageing and work steps were delivered with 
the samples, so that all laboratories treated the samples the same way, especially in terms of thermal history. Therefore, influence of different handling of the samples in the participating laboratories could be kept to a minimum. The work instructions are summarized below

The original binder sample of $2.5 \mathrm{~kg}$ was first heated to $160{ }^{\circ} \mathrm{C}$ and divided into two equal portions, since each participant was assigned a work program that contained two RTFOT ageing temperatures. The samples were cooled down to room temperature subsequently. Before RTFOT ageing, the binder was reheated to $160{ }^{\circ} \mathrm{C}$ for $60 \mathrm{~min}$, so that the initial conditions for the different RTFOT ageing temperatures were the same for all tests. From the liquid binder, different portions were poured into appropriate sample containers to perform mechanical testing (penetration, softening point and dynamic shear rheometer [DSR]) of the virgin binder. Additionally, $10 \mathrm{~g}$ were separated into a metal can for FTIR measurements of the virgin binder characteristics. Three RTFOT runs were needed at each temperature to condition sufficient binder to perform all the subsequent tests on aged samples. After the RTFOT ageing step was completed, the binder was again collected in a metal can, homogenized, and cooled down to room temperature. The sample was then reheated to $160{ }^{\circ} \mathrm{C}$ for $60 \mathrm{~min}$ and binder for the different tests was poured, including for FTIR. $250 \mathrm{~g}$ of the RTFOT aged binder went into 5 PAV pans and were PAV aged according to EN 14769 [47]. After the PAV ageing step the pan holders were then put into the oven for $30 \mathrm{~min}$ at $170{ }^{\circ} \mathrm{C}$ to degas the binder. Then, all pans were poured into one metal can and stirred to homogenize the sample. The PAV aged sample was then poured into the appropriate containers for testing including FTIR.

\subsection{FTIR analysis}

While a common sample preparation method was defined for all laboratories, each performed the IR spectrometry using their own standard protocol. A survey between the laboratories has shown that all but one used reflectance mode (ATR) and that almost all used different devices and software for data collection from FTIR. Laboratory 6 used transmission mode for IR analysis. Five laboratories used diamond crystal and three laboratories used zinc selenide crystal. In addition, it was common practice to have some preprocessing or calibration before running the analysis.

In terms of test conditions, there was only little variation between the different laboratories. The analysis itself is carried out at room temperature as reported between 18 and $25{ }^{\circ} \mathrm{C}$. The test duration is less than $5 \mathrm{~min}$, most likely within a minute between the time the sample is placed on the crystal and measurement done. The number of scan was 32 for three laboratories, 64 for four laboratories and 24 scans for one laboratory. The resolution was $4 \mathrm{~cm}^{-1}$ between 4000 and $400 \mathrm{~cm}^{-1}$ wave length for all participating laboratories.

All raw spectra data were submitted by the participating laboratories in a common format. The spectra were merged together and analyzed by one user applying the same analysis methods on all spectra. In this way, any impact of variation of the analysis methods on results could be prevented. The spectra were investigated to obtain information on changes in the chemical composition by oxidative ageing. Therefore, changes in the carbonyl $(\mathrm{C}=\mathrm{O})$ and sulfoxide $(\mathrm{S}=\mathrm{O})$ area were taken into consideration. The carbonyl area is commonly defined as the band around the $1680 \mathrm{~cm}^{-1}$ peak, whereas the sulfoxide area is the band around $1030 \mathrm{~cm}^{-1}$. The aliphatic group (symmetric and asymmetric bending vibrations around 1460 and $1376 \mathrm{~cm}^{-1}$, respectively) is commonly used as a reference group, since it is anticipated that these structures are stable and not affected by applied ageing procedures [51]. The use of a reference group is based on the idea to remove any variation in the absorbance spectra due to a variation of the IR beam penetration between samples, which would bias further interpretation of results.

The spectral analysis was carried out using an integration method which considers the area below the absorbance spectrum around a band maximum. Two state of the art approaches were taken in terms of baseline for integration: (a) the absolute baseline at an absorbance value of 0 and (b) a tangential approach where a relative base line is chosen for each band in a way that the relative base line approaches the spectrum in a tangential way. An FTIR example spectrum indicating all considered structural groups and showing examples of base and tangential integration analysis is presented in Fig. 1.

The integrals from absolute and tangential baseline are defined as follows: 
$I_{i, \text { base }}=\int_{w_{l, i}}^{w_{u, i}} a(w) \mathrm{d} w$

$I_{i, \tan }=\int_{w_{l, i}}^{w_{u, i}} a(w) \mathrm{d} w-\frac{a\left(w_{u, i}\right)+a\left(w_{l, i}\right)}{2} \cdot\left(w_{u, i}-w_{l, i}\right)$

with $a(w)$ absorbance value at wavenumber $w, w_{u, i}$ upper wavenumber limit for structural group $i, w_{l, i}$ lower wavenumber limit for structural group $i, I_{i, \text { base }}$ integrated area from absolute base line for structural group $i, I_{i, \tan }$ integrated area from tangential base line for structural group $i$.

The lower and upper wave numbers for the structural groups were defined as follows:

- Carbonyl 1660-1753 $\mathrm{cm}^{-1}$

- Sulfoxide $970-1070 \mathrm{~cm}^{-1}$

- Reference (aliphatic) $1350-1525 \mathrm{~cm}^{-1}$

It is to be noted that these upper and lower wave numbers are not absolute and they occur around the peaks mentioned earlier and are material dependent.

From the integrals defined in Eqs. (1) and (2), the carbonyl and sulfoxide indices that are an indication of oxidation are obtained as shown below:

$$
\begin{gathered}
\mathrm{ICO}_{\text {base }}=\frac{I_{\mathrm{CO}, \text { base }}}{I_{\text {ref, base }}} \quad \mathrm{ISO}_{\text {base }}=\frac{I_{\mathrm{SO}, \text { base }}}{I_{\text {ref, base }}} \\
\mathrm{ICO}_{\tan }=\frac{I_{\mathrm{CO}, \text { tan }}}{I_{\mathrm{ref}, \tan }} \quad \mathrm{ISO}_{\mathrm{tan}}=\frac{I_{\mathrm{SO}, \text { tan }}}{I_{\mathrm{ref}, \tan }}
\end{gathered}
$$

\section{Results and discussion}

Figure 2 shows FTIR spectra from all unaged binder samples obtained by Laboratory 9 in order to analyze any qualitative differences in the virgin binders. The spectra are stacked starting with B501A on the bottom to B504A on top to make them better distinguishable. While binders B501 to B503 do not show visible differences especially in the relevant bands for oxidation, B504 is different from the other three samples at various positions in the spectrum: in the low wavenumber area below $800 \mathrm{~cm}^{-1}$ which is characteristic for aromatic structures, as well as in the sulfoxide area with a lower absorbance and in the carbonyl area with stronger absorbance.

To show the impact of RTFOT and RTFOT + PAV ageing in terms of qualitative changes in FTIR spectra, Fig. 3 contains two diagrams with samples B501 and B504. The reason for choosing these two samples is that B501, B502 and B503 exhibit similar
Fig. 1 Example of FTIR absorbance spectrum for an RTFOT + PAV aged binder sample

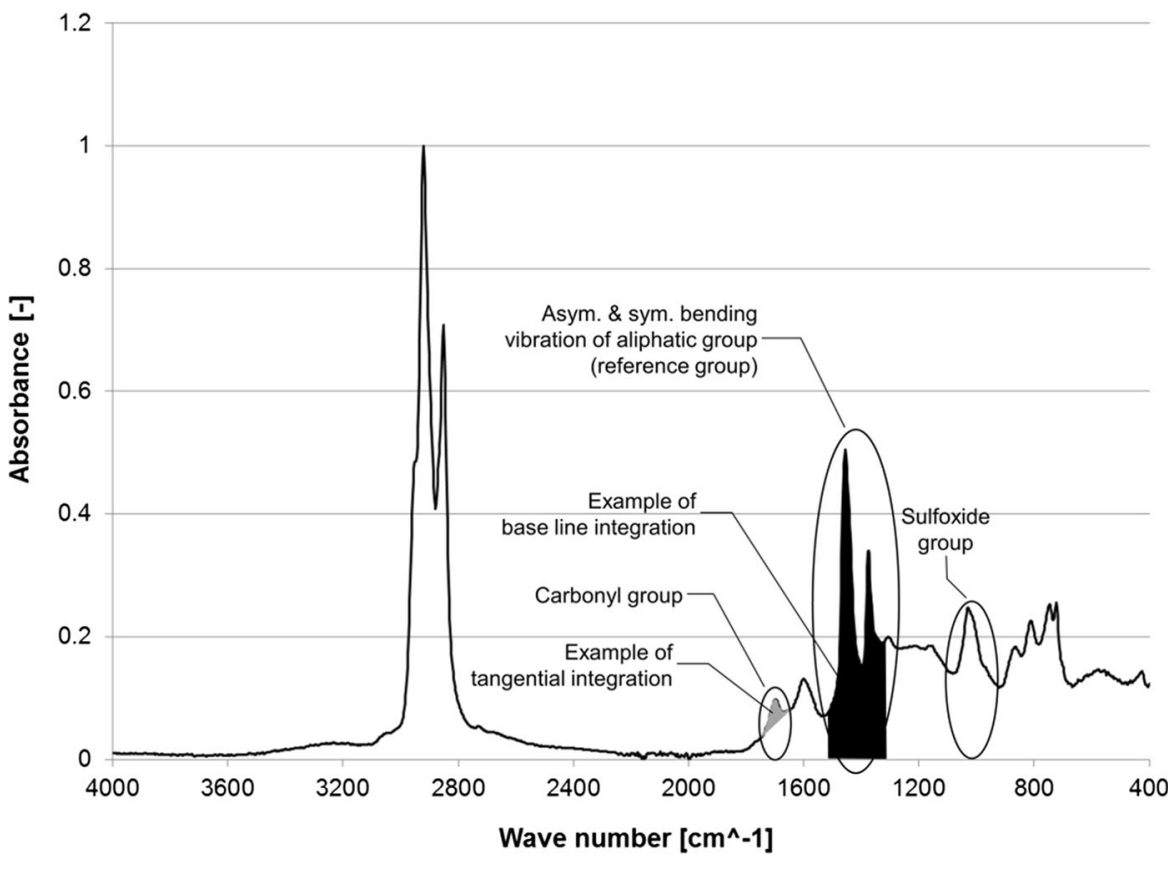




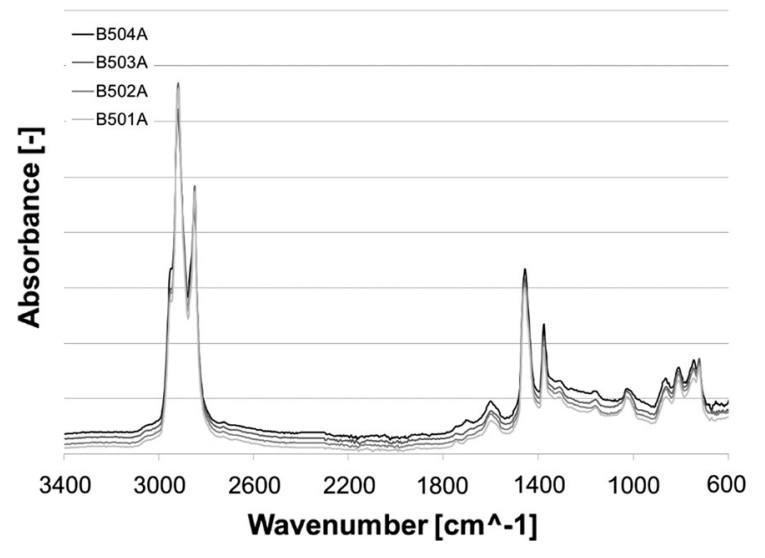

Fig. 2 FTIR spectra of all unaged binder samples from Laboratory 9

spectra, whereas B504 shows some noteworthy differences. Each diagram shows stacked spectra from the unaged sample (light grey), as well as from the RTFOT aged sample at $163{ }^{\circ} \mathrm{C}$ (dark grey) and from the RTFOT + PAV aged sample (black). The spectra from Laboratory 9 were zoomed into show only the relevant wavenumber range from 900 to $1800 \mathrm{~cm}^{-1}$. Vertical markers in the diagrams indicate expected band maxima for carbonyl and sulfoxide bands. B504 shows a distinct absorbance in the carbonyl area even in the unaged state. Since the distinct carbonyl area in B504A occurs in spectra from all 9 laboratories, an error, e.g. due to excessive heating prior to FTIR analysis by Laboratory 9 is highly unlikely. The carbonyl group includes a wide range of species, amongst others ester of acid which may be already
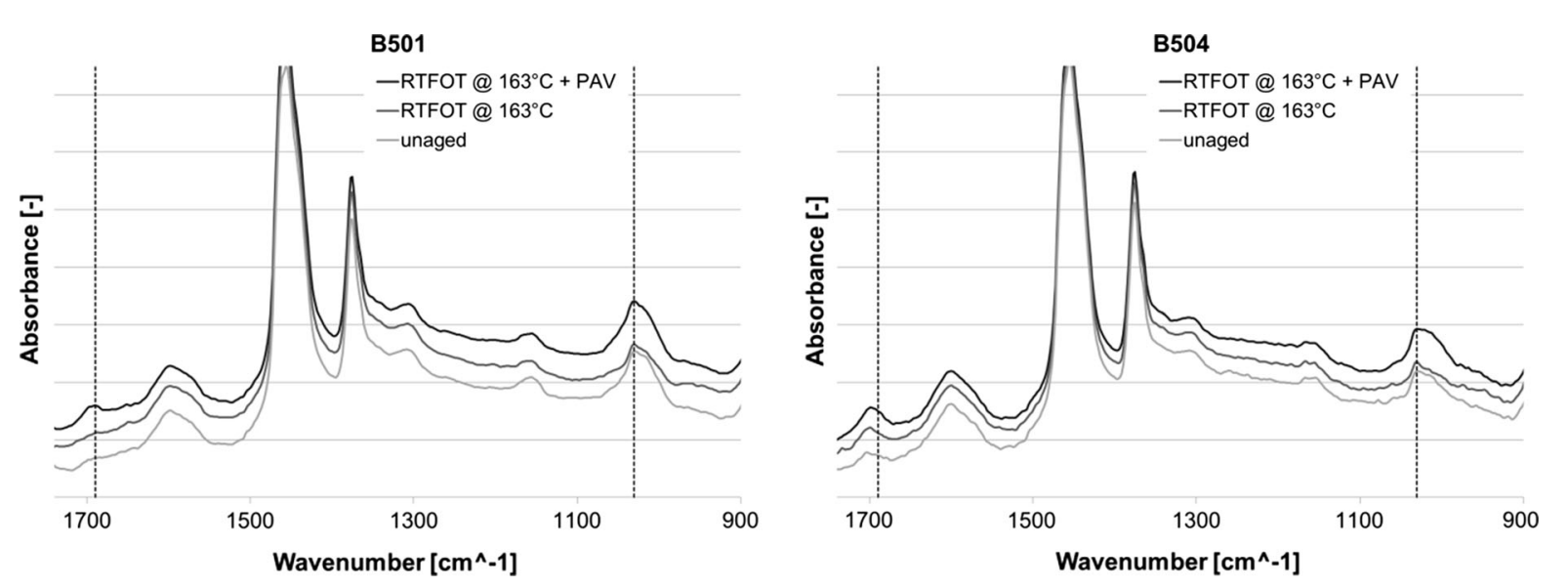

Fig. 3 FTIR spectra of B501 and B504 unaged, RTFOT $\left(163{ }^{\circ} \mathrm{C}\right)$ aged and RTFOT $\left(163{ }^{\circ} \mathrm{C}\right)+$ PAV aged binder samples from Laboratory 9 inherent from the original binder. Thus, the carbonyl peak in the unaged state of B504A is most probably linked to the nature of the bitumen itself either from the origin of the crude oil or the refining process $[52,53]$.

RTFOT ageing at $163{ }^{\circ} \mathrm{C}$ does not lead to a visible increase in the carbonyl area, only after PAV ageing, a distinct band for carbonyl structures can be detected. Interestingly enough, the band maximum of the carbonyl area is slightly shifted for the B504 sample. This is already an important result that the carbonyl peak is not an absolute indicator of oxidation but its increase is a relative indicator of oxidation.

As for the sulfoxide area, all binder samples show absorbance in this band already in the unaged state. The sulfoxide area tends to decrease upon RTFOT ageing and increase again after PAV ageing.

Binder B504A is a valuable sample for this study, since it is the only one that was tested by all 9 participating laboratories to compare spectra received from all laboratories. In addition, since it was tested in its unaged state, any impact of differences in RTFOT and PAV ageing carried out by the different laboratories can be prevented. Figure 4 (top left) shows the spectra as received from the participants in one diagram. The labeling in the spectra follows the sequence of absorbance spectra.

The principal evolution of the absorbance with wavenumber is quite similar for most of the laboratories, Laboratory 6 being an exception since it used transmission mode for IR spectroscopy. All spectra show similar spectra in the aromatic structures range, 

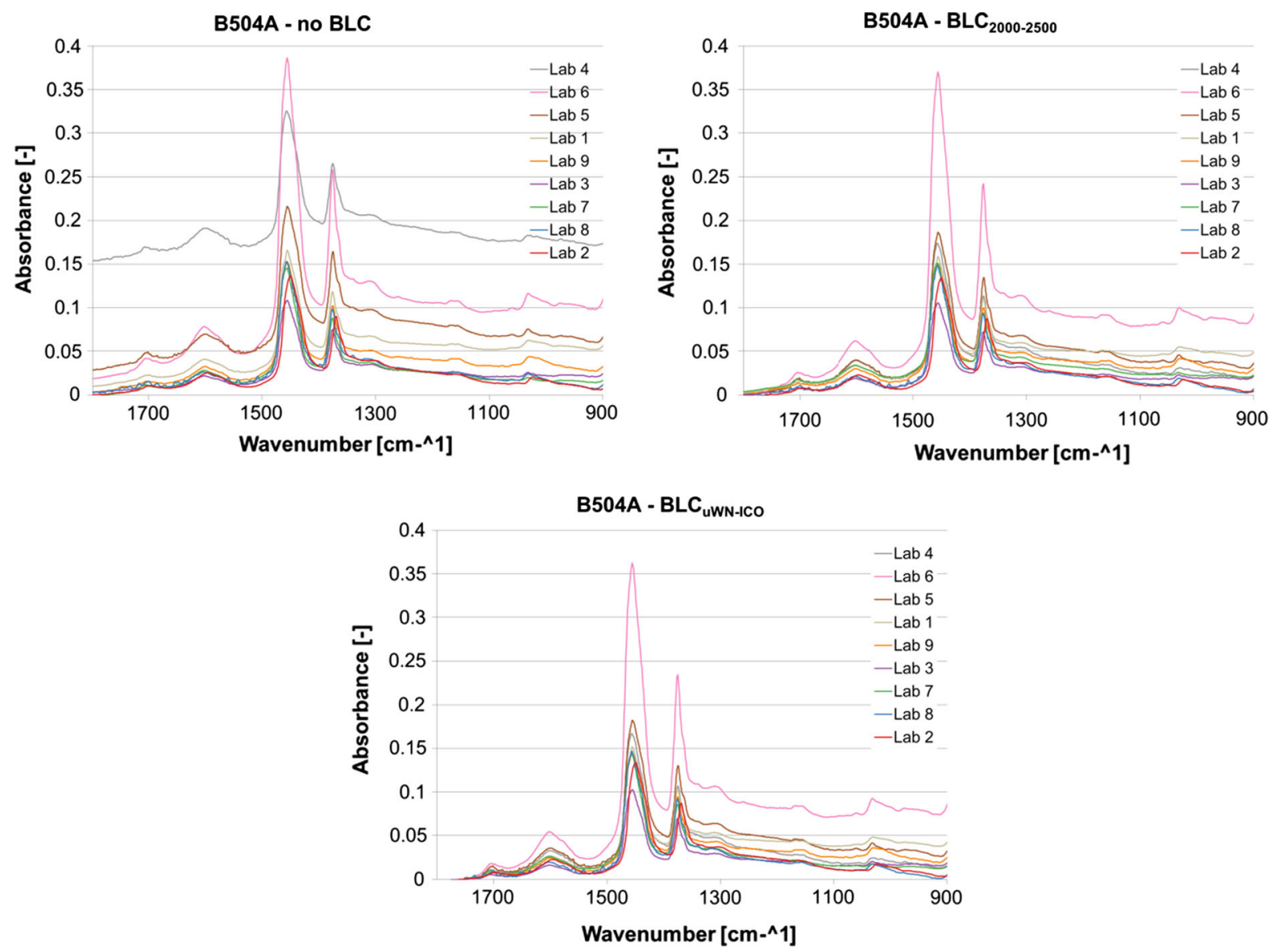

Fig. 4 FTIR spectra of B504A from all participating laboratories, no BLC (top left), BLC $2000-2500$ (top right), BLC uWN-ICO $_{\text {(bottom) }}$

as well as sulfoxide and carbonyl structures. Also, the aliphatic absorbance band is similar for all laboratories. However, the laboratories differ significantly in terms of their baseline absorbance in the wavenumber range between 2000 and $2500 \mathrm{~cm}^{-1}$. The data in the top left diagram in Fig. 4 shows that a baseline correction may be necessary to bring spectra from different laboratories closer together and therefore enhance comparability of results derived from the spectra.

\subsection{Improving reproducibility}

Reproducibility referring to comparability of results from different laboratories and repeatability referring results from the same laboratory are important considerations for any experimental method. Assessing the reproducibility of the FTIR method for bitumen is a key result of this round robin test.
Although the number of participating laboratories (9) was relatively small for a round robin test, a statistical investigation into the reproducibility of FTIR spectra analysis based on the accumulated data is valuable.

To assess the reproducibility, the coefficient of variation $(\mathrm{CV})$ was taken as a benchmark parameter. Carbonyl and sulfoxide indices were calculated using Eqs. (1)-(4) for each spectrum from each laboratory. Mean values (MV) and standard deviations (SD) for each index and the CV were calculated as the SD relative to the $\mathrm{MV}$ in \%. The lower the $\mathrm{CV}$, i.e. the lower the scattering of results among the laboratories, the higher is the reproducibility of an index.

Since it was seen from a first visual inspection of the gathered spectra (see e.g. top left diagram in Fig. 4) that they vary strongly in absorbance baseline, three different approach in terms of baseline correction (BLC) were compared: (a) no baseline correction (use spectra as obtained), (b) baseline correction 
between wavenumber 2000 and $2500 \mathrm{~cm}^{-1}$ and (c) baseline correction at the upper wavenumber limit for the carbonyl area $\left(1753 \mathrm{~cm}^{-1}\right)$. The base line corrections (b) and (c) are carried out according to the following equations:

$$
\begin{aligned}
& \mathrm{BLC}_{2000-2500}: \int_{2000}^{2500}\left(a(w)-c_{1}\right) \mathrm{d} w=0 \\
& \mathrm{BLC}_{u \mathrm{WN}-\mathrm{ICO}}: a\left(w_{u, \mathrm{CO}}\right)-c_{2}=0 \mid w_{u, \mathrm{CO}}=1753
\end{aligned}
$$

with $a(w)$ absorbance value at wavenumber $w, c_{1}$ constant for $\mathrm{BLC}_{2000-2500}, w_{u, C O}$ upper wavenumber limit for carbonyl band, $c_{2}$ constant for $\mathrm{BLC}_{\mathrm{uWN}-\mathrm{ICO} \text {. }}$

Equations (5) and (6) are solved, so that $c_{1}$ and $c_{2}$ are derived for spectra from each laboratory and these constants are subsequently used to shift spectra and realize the baseline correction. Figure 4 shows B504A spectra from all laboratories with no BLC, $\mathrm{BLC}_{2000-}$ 2500 and $\mathrm{BLC}_{\mathrm{uWN}-\mathrm{ICO}}$ in the relevant wavenumber range from 900 to $1800 \mathrm{~cm}^{-1}$.

With the three methods at hand, one without baseline correction and two with different baseline correction approaches the carbonyl and sulfoxide indices were calculated for all spectra obtained by the different laboratories for all cases. MV, SD and CV were derived from the calculated indices and $\mathrm{CV}$ was used to assess reproducibility.

Table 3 contains the $\mathrm{CVs}$ for $\mathrm{ICO}_{\text {base }}, \mathrm{ICO}_{\text {tan }}$, $\mathrm{ISO}_{\text {base }}$ and $\mathrm{ISO}_{\mathrm{tan}}$, respectively. For this analysis, only those cases were taken into account where the number of spectra from different laboratories (sample size) is equal or larger than 6 to have a large enough sample size for deriving meaningful CVs. Numbers highlighted in bold show the lowest CV (best reproducibility) for the two ICO and the two ISO indices, respectively.

Looking at the reproducibility of $\mathrm{ICO}_{\text {base }}$, in case no baseline correction was applied, the $\mathrm{CV}$ is above $60 \%$ in half of the considered cases and still above $40 \%$ for most cases. Using $\mathrm{BLC}_{2000-2500}$, the $\mathrm{CV}$ can be decreased significantly; it does not exceed $60 \%$ in any case. Best reproducibility can be achieved, when BLC $_{\mathrm{uWN}-\mathrm{ICO}}$ is applied. CVs are around or below $20 \%$ for most cases. In addition, it becomes obvious from the data that higher ICOs (PAV aged state) lead to best reproducibility with $\mathrm{CV}$ s below $15 \%$ and lower ICOs (unaged state) tend to show worse CVs even above $20 \%$ for some cases.

Comparing CVs from $\mathrm{ICO}_{\text {tan }}$ to $\mathrm{ICO}_{\text {base }}, \mathrm{ICO}_{\text {tan }}$ is influenced by the applied baseline correction method to a much lesser degree than $\mathrm{ICO}_{\text {base }}$. This is understandable since with tangential integration, the baseline for integration is independent of the spectral baseline. However, in all considered cases, $\mathrm{ICO}_{\tan }$ led to significantly worse reproducibility ( $\mathrm{CVs}$ ranging from 20 to $120 \%$ ) compared to $\mathrm{ICO}_{\text {base }}$ Looking at data from $\mathrm{ISO}_{\text {base }}$ and $\mathrm{ISO}_{\mathrm{tan}}$, in the majority of the considered cases both sulfoxide indices were not affected by the baseline correction method. In over half of the considered cases, $\mathrm{ICO}_{\text {base }}$ led to lower $\mathrm{CVs}$ than $\mathrm{ICO}_{\tan }$. Thus, the given data support the use of integrated indices from absolute base line $\left(\mathrm{ICO}_{\text {base }}\right.$ $\mathrm{ISO}_{\text {base }}$ ) with baseline correction method $\mathrm{BLC}_{\mathrm{uWN}-\mathrm{ICO}}$ to improve reproducibility and thus comparability of data between different laboratories.

The best case results for CVs for reproducibility (10-20\% for $\mathrm{ICO}_{\text {base }}$ ) are fairly higher than CVs reported previously for repeatability (see [44]: $3.0-5.5 \%$ for $\mathrm{ICO}_{\text {base }}$ ). It has to be taken into account that the reproducibility in this case is not only affected by FTIR but also by preceding ageing procedures RTFOT and PAV that were applied to all binder samples in the participating laboratory. Although RTFOT and PAV were carried out according to the European Standards and in addition, detailed work instructions set binder handling and ageing conditions even more strictly, a certain amount of scattering in the data will have to be attributed to unavoidable differences in laboratory ageing of the binder samples. Taking the three unaged samples (B501A, B502A and B504A) into account which are not affected by any ageing procedure, the reproducibility of these samples is still poorer (11-28\%) than the reported repeatability in [44]. Thus, the poorer reproducibility is only partly affected by the preceding ageing procedures. Another part is due to the use of different devices and different operators, respectively.

\subsection{Impact of RTFOT temperature on short- and long-term ageing}

Employing the findings about optimal approach for high reproducibility in Sect. 3.1, the oxidation indices $\left(\mathrm{ICO}_{\text {base }}\right.$ and $\mathrm{ISO}_{\text {base }}$ ) were calculated from $\mathrm{BLC}_{\mathrm{uWN}}$ ICO corrected spectra for all binder samples from all 
Table $3 \mathrm{CV}$ for $\mathrm{ICO}_{\text {base }}, \mathrm{ICO}_{\mathrm{tan}}, \mathrm{ISO}_{\text {base }}, \mathrm{ISO}_{\tan }$ for all applied baseline correction methods

\begin{tabular}{|c|c|c|c|c|c|c|c|c|c|c|c|c|c|c|}
\hline & B501A & $\begin{array}{l}\text { B501B_ } \\
123\end{array}$ & $\begin{array}{l}\text { B501B_ } \\
163\end{array}$ & $\begin{array}{l}\text { B501C } \\
123\end{array}$ & $\begin{array}{l}\text { B501C_ } \\
163\end{array}$ & B502A & $\begin{array}{l}\text { B502B_ } \\
163\end{array}$ & $\begin{array}{l}\text { B502C_ } \\
163\end{array}$ & B503A & B504A & $\begin{array}{l}\text { B504B_ } \\
123\end{array}$ & $\begin{array}{l}\text { B504B_ } \\
163\end{array}$ & $\begin{array}{l}\text { B504C } \\
123\end{array}$ & $\begin{array}{l}\text { B504C_ } \\
163\end{array}$ \\
\hline \multicolumn{15}{|l|}{ ICO-base } \\
\hline no BLC & $76 \%$ & $106 \%$ & $58 \%$ & $79 \%$ & $44 \%$ & $64 \%$ & $29 \%$ & $31 \%$ & $41 \%$ & $71 \%$ & $99 \%$ & $33 \%$ & $64 \%$ & $38 \%$ \\
\hline $\operatorname{BLC}(2000-2500)$ & $47 \%$ & $46 \%$ & $40 \%$ & $28 \%$ & $29 \%$ & $48 \%$ & $25 \%$ & $19 \%$ & $56 \%$ & $26 \%$ & $35 \%$ & $18 \%$ & $25 \%$ & $15 \%$ \\
\hline BLC(UWN-ICO) & $22 \%$ & $23 \%$ & $19 \%$ & $15 \%$ & $14 \%$ & $28 \%$ & $21 \%$ & $10 \%$ & $30 \%$ & $11 \%$ & $18 \%$ & $10 \%$ & $14 \%$ & $10 \%$ \\
\hline \multicolumn{15}{|l|}{ ICO-tang } \\
\hline no $B L C$ & $92 \%$ & $38 \%$ & $163 \%$ & $35 \%$ & $39 \%$ & $45 \%$ & $101 \%$ & $20 \%$ & $110 \%$ & $30 \%$ & $44 \%$ & $18 \%$ & $23 \%$ & $21 \%$ \\
\hline $\operatorname{BLC}(2000-2500)$ & $97 \%$ & $44 \%$ & $134 \%$ & $43 \%$ & $38 \%$ & $36 \%$ & $85 \%$ & $21 \%$ & $104 \%$ & $29 \%$ & $27 \%$ & $18 \%$ & $21 \%$ & $20 \%$ \\
\hline BLC (UWN-ICO) & $91 \%$ & $43 \%$ & $119 \%$ & $48 \%$ & $40 \%$ & $33 \%$ & $81 \%$ & $22 \%$ & $90 \%$ & $32 \%$ & $27 \%$ & $19 \%$ & $22 \%$ & $21 \%$ \\
\hline \multicolumn{15}{|l|}{ ISO-base } \\
\hline no BLC & $31 \%$ & $37 \%$ & $30 \%$ & $29 \%$ & $24 \%$ & $40 \%$ & $28 \%$ & $25 \%$ & $38 \%$ & $37 \%$ & $40 \%$ & $31 \%$ & $28 \%$ & $22 \%$ \\
\hline BLC (2000-2500) & $32 \%$ & $32 \%$ & $25 \%$ & $19 \%$ & $20 \%$ & $38 \%$ & $29 \%$ & $26 \%$ & $37 \%$ & $35 \%$ & $26 \%$ & $34 \%$ & $23 \%$ & $23 \%$ \\
\hline BLC(UWN-ICO) & $33 \%$ & $33 \%$ & $28 \%$ & $21 \%$ & $22 \%$ & $40 \%$ & $29 \%$ & $26 \%$ & $38 \%$ & $39 \%$ & $28 \%$ & $35 \%$ & $26 \%$ & $24 \%$ \\
\hline \multicolumn{15}{|l|}{ ISO-tang } \\
\hline no BLC & $37 \%$ & $72 \%$ & $23 \%$ & $26 \%$ & $29 \%$ & $29 \%$ & $24 \%$ & $10 \%$ & $29 \%$ & $59 \%$ & $50 \%$ & $19 \%$ & $18 \%$ & $8 \%$ \\
\hline $\operatorname{BLC}(2000-2500)$ & $41 \%$ & $78 \%$ & $23 \%$ & $30 \%$ & $29 \%$ & $29 \%$ & $25 \%$ & $11 \%$ & $29 \%$ & $63 \%$ & $52 \%$ & $20 \%$ & $21 \%$ & $7 \%$ \\
\hline BLC (UWN-ICO) & $41 \%$ & $79 \%$ & $23 \%$ & $30 \%$ & $29 \%$ & $29 \%$ & $25 \%$ & $11 \%$ & $29 \%$ & $64 \%$ & $54 \%$ & $19 \%$ & $22 \%$ & $7 \%$ \\
\hline
\end{tabular}

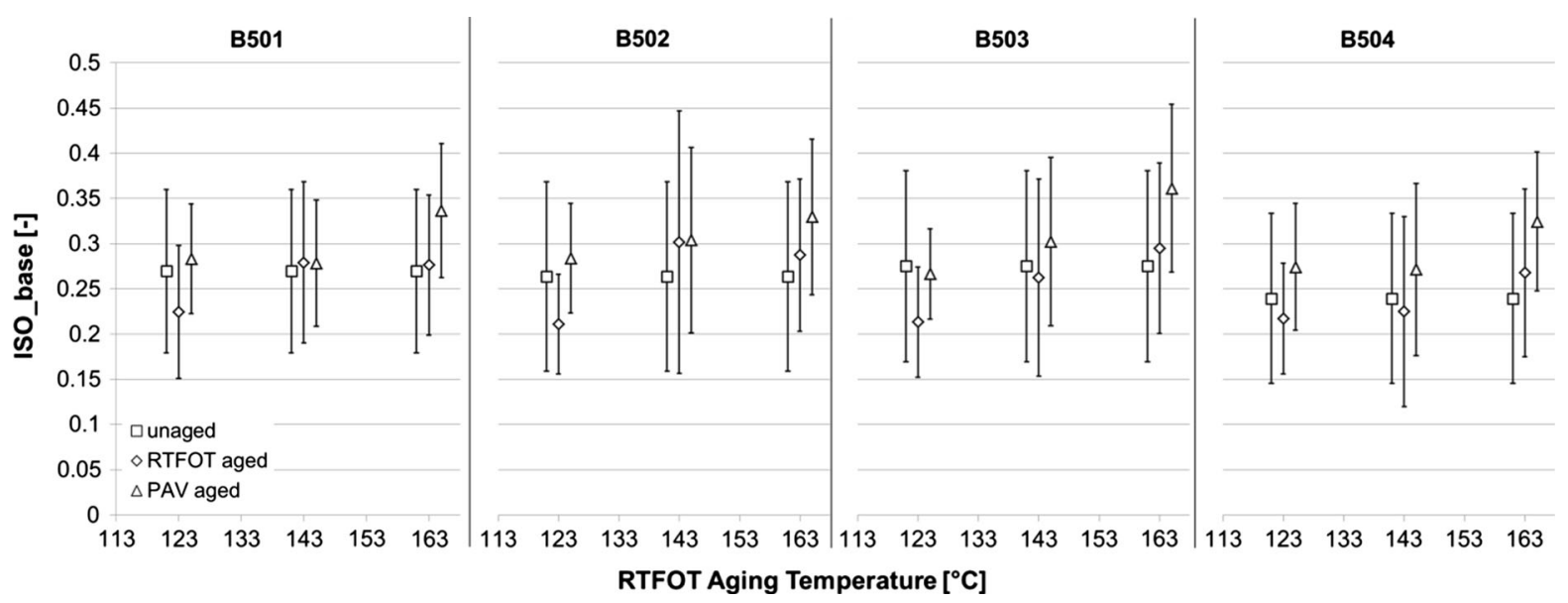

Fig. 5 Evolution of $\mathrm{ICO}_{\text {base }}$ from $\mathrm{BLC}_{\mathrm{uWN}-\mathrm{ICO}}$ with RTFOT temperature

participating laboratories. Figure 5 contains $\mathrm{ICO}_{\text {base }}$ from B501 to B504 and Fig. 6 shows ISO $_{\text {base versus }}$ RTFOT ageing temperature. The data in the diagrams are MV, error bars represent SD. In addition, Tables 4 and 5 contain a statistical analysis of results for ICO and ISO, respectively. A statistical $t$ test [54] was carried out to investigate significance of differences between indices from different ageing states. Cells highlighted in bold indicate test values below a significance level alpha of 0.05 . Thus, highlighted cells show that the respective indices are significantly different.

Combining information from Fig. 5 and Table 4 for the carbonyl index, hardly any changes in ICO can be observed due to RTFOT ageing. There is an increasing trend for B504, but the differences between unaged and RTFOT aged state are not significant. The data shown in the diagrams and tables do not show a significant impact of RTFOT temperature on shortterm or long-term aged material regardless of the RTFOT temperature used. PAV aged samples show significantly higher carbonyl indices compared to RTFOT and unaged samples. However, no significant differences between PAV aged samples from RTFOT aged samples at different temperatures could be found.

Comparing B504 to the other three binder samples, B504 shows clearly higher ICOs in all ageing states with ICOs being about 0.01 higher than the other three 


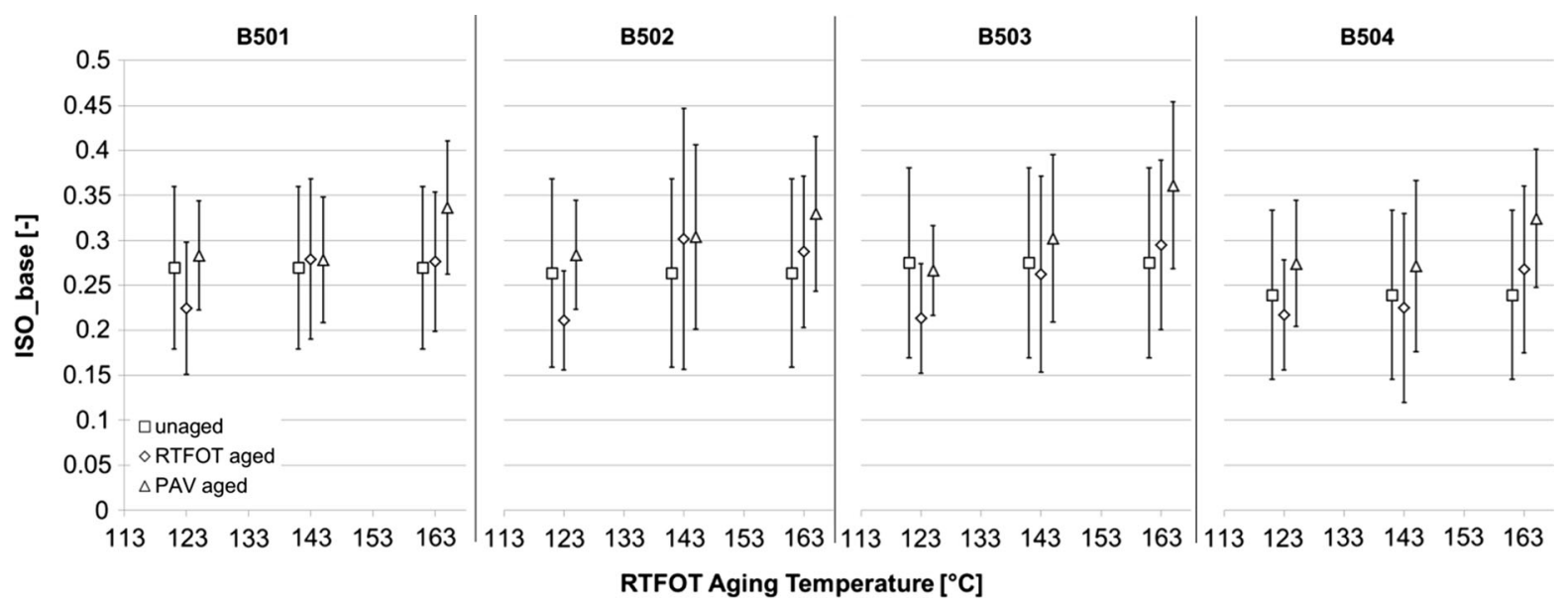

Fig. 6 Evolution of $\mathrm{ISO}_{\text {base }}$ from $\mathrm{BLC}_{\mathrm{uWN}-\mathrm{ICO}}$ with RTFOT temperature

binders. This is in line with visual assessment of B504 spectra (Fig. 3) with significant carbonyl bands even in the unaged state as discussed earlier. The results for all four types of binders show that after RTFOT in some cases there is a slight reduction in ICO.

Analysis of changes in the carbonyl bands due to oxidative ageing by FTIR is a discriminant approach when the rather large changes, i.e. from an unaged or short-term aged to a long-term aged state, are considered. Impacts of changes in the short-term ageing temperature on short- or long-term aged samples could not be found by this investigation. Differences between different binder sources can be detected, as shown for the case of B504 compared to the other three binder samples.

Figure 6 and Table 5 show results from the sulfoxide indices vs. RTFOT temperature. Due to the rather small changes with ageing and the larger scattering of results, no significant changes can be found, with one exception, which is from RTFOT aged sample at $123{ }^{\circ} \mathrm{C}$ to PAV aged sample after RTFOT at $163{ }^{\circ} \mathrm{C}$. Still, it is interesting that certain trends are observable and are consistent for all four binder samples. In all cases, an RTFOT at $123{ }^{\circ} \mathrm{C}$ leads to a decrease of ISO, whereas ISO stays mostly constant at an RTFOT at $143{ }^{\circ} \mathrm{C}$ and increases for RTFOT at $163{ }^{\circ} \mathrm{C}$. As for PAV, there is an increase after RTFOT at $123{ }^{\circ} \mathrm{C}$, as well as at 143 and $163{ }^{\circ} \mathrm{C}$. The increase tends to be stronger with increasing RTFOT temperature. Thus, the data show that RTFOT temperature and therefore mix production temperature has a stronger impact on the formation of sulfoxide structures than for carbonyl structures. Also, the long-term aged state after PAV is affected by the short-term ageing temperature.

\section{Summary, conclusions and recommendations}

This paper presents part of an extensive study on the link between chemical structure and mechanical behavior of bituminous binders carried out by RILEM TC 252 CMB. For the study, a round robin testing program with participation from 9 laboratories, was carried out on four $70 / 100$ pen graded binders from different sources. The samples were short-term aged by RTFOT at three different temperatures $(123,143$, $163{ }^{\circ} \mathrm{C}$ ) and long-term aged by PAV for $20 \mathrm{~h}$ at 2.1 MPa and $100{ }^{\circ} \mathrm{C}$. With these samples, impacts of short-term ageing temperature on chemical changes due to short- and long-term ageing of bituminous binders could be investigated. These impacts are of particular interest for the industry, since the market share of warm-mix asphalt mixes (WMA) with decreased production temperatures gains increasing importance, but the impact of lower production temperatures (short-term ageing) on the long-term behavior has not been studied thoroughly yet. Samples were investigated by mechanical tests as well as chemical tests using FTIR analysis. This paper shows an in-depth analysis of the received FTIR spectra from the round robin study. The main purpose of the presented work is to look into methods on how to improve the reproducibility and thus comparability of 
Table 4 Results of t-test for $\mathrm{ICO}_{\text {base }}$ from $\mathrm{BLC}_{\mathrm{uWN}}$ ICO for all binder samples (highlighted are test values below a significance level alpha of 0.05)

\begin{tabular}{lllllll}
\hline ICO_base & B501A & B501B_123 & B501B_143 & B501B_163 & B501C_123 & B501C_143 \\
\hline B501B_123 & $4.6 \mathrm{E}-01$ & & & & & \\
B501B_143 & $2.5 \mathrm{E}-01$ & $6.6 \mathrm{E}-01$ & & & & \\
B501B_163 & $1.3 \mathrm{E}-01$ & $\mathbf{4 . 3 E}-\mathbf{0 2}$ & $\mathbf{2 . 7 E}-\mathbf{0 2}$ & & & \\
B501C_123 & $\mathbf{7 . 8 E}-\mathbf{0 5}$ & $\mathbf{8 . 4 E}-\mathbf{0 5}$ & $\mathbf{2 . 8 E}-\mathbf{0 4}$ & $\mathbf{1 . 2 E}-\mathbf{0 3}$ & & \\
B501C_143 & $\mathbf{3 . 2 E}-\mathbf{0 4}$ & $\mathbf{4 . 1 E}-\mathbf{0 4}$ & $\mathbf{1 . 7 E}-\mathbf{0 3}$ & $\mathbf{2 . 4 E}-\mathbf{0 3}$ & $6.2 \mathrm{E}-01$ & \\
B501C_163 & $\mathbf{7 . 6 E}-\mathbf{0 6}$ & $\mathbf{1 . 0 E}-\mathbf{0 5}$ & $\mathbf{4 . 6 E}-\mathbf{0 5}$ & $\mathbf{1 . 5 E}-\mathbf{0 4}$ & $5.6 \mathrm{E}-01$ & 9.7E-01 \\
\hline ICO_base & B502A & B502B_123 & B502B_143 & B502B_163 & B502C_123 & B502C_143 \\
\hline B502B_123 & $9.4 \mathrm{E}-01$ & & & & & \\
B502B_143 & $7.0 \mathrm{E}-02$ & $8.0 \mathrm{E}-02$ & & & & \\
B502B_163 & $1.2 \mathrm{E}-01$ & $1.2 \mathrm{E}-01$ & $3.5 \mathrm{E}-01$ & & & \\
B502C_123 & $\mathbf{6 . 0 E}-\mathbf{0 4}$ & $\mathbf{1 . 1 E}-\mathbf{0 3}$ & $9.2 \mathrm{E}-02$ & $\mathbf{4 . 8 E}-\mathbf{0 3}$ & & \\
B502C_143 & $\mathbf{8 . 1 E}-\mathbf{0 5}$ & $\mathbf{3 . 1 E}-\mathbf{0 4}$ & $\mathbf{3 . 4 E}-\mathbf{0 2}$ & $\mathbf{5 . 3 E}-\mathbf{0 4}$ & $1.6 \mathrm{E}-01$ & \\
B502C_163 & $\mathbf{3 . 3 E}-\mathbf{0 6}$ & $\mathbf{1 . 1 E}-\mathbf{0 5}$ & $\mathbf{1 . 7 E}-\mathbf{0 2}$ & $\mathbf{5 . 3 E}-\mathbf{0 5}$ & $4.6 \mathrm{E}-01$ & 2.3E-01 \\
\hline ICO_base & B503A & B503B_123 & B503B_143 & B503B_163 & B503C_123 & B503C_143 \\
\hline B503B_123 & $5.0 \mathrm{E}-01$ & & & & & \\
B503B_143 & $6.3 \mathrm{E}-01$ & $2.5 \mathrm{E}-01$ & & & & \\
B503B_163 & $4.7 \mathrm{E}-01$ & $8.8 \mathrm{E}-02$ & $9.1 \mathrm{E}-01$ & & & \\
B503C_123 & $\mathbf{5 . 5 E}-\mathbf{0 3}$ & $\mathbf{2 . 6 E}-\mathbf{0 3}$ & $\mathbf{2 . 2 E}-\mathbf{0 2}$ & $\mathbf{7 . 6 E}-\mathbf{0 3}$ & & \\
B503C_143 & $\mathbf{1 . 0 E}-\mathbf{0 3}$ & $\mathbf{9 . 8 E}-\mathbf{0 4}$ & $\mathbf{8 . 3 E}-\mathbf{0 3}$ & $\mathbf{1 . 4 E}-\mathbf{0 3}$ & $2.2 \mathrm{E}-01$ & \\
B503C_163 & $\mathbf{2 . 5 E}-\mathbf{0 3}$ & $\mathbf{1 . 6 E}-\mathbf{0 3}$ & $\mathbf{1 . 2 E}-\mathbf{0 2}$ & $\mathbf{3 . 6 E}-\mathbf{0 3}$ & $4.6 \mathrm{E}-01$ & $6.3 \mathrm{E}-01$ \\
\hline ICO_base & B504A & B504B_123 & B504B_143 & B504B_163 & B504C_123 & B504C_143 \\
\hline B504B_123 & $1.6 \mathrm{E}-01$ & & & & & \\
B504B_143 & $\mathbf{3 . 3 E - 0 2}$ & $5.2 \mathrm{E}-01$ & & & & \\
B504B_163 & $\mathbf{3 . 0 E}-\mathbf{0 4}$ & $9.6 \mathrm{E}-02$ & $3.0 \mathrm{E}-01$ & & & \\
B504C_123 & $\mathbf{2 . 5 E}-\mathbf{0 6}$ & $\mathbf{1 . 8 E}-\mathbf{0 4}$ & $\mathbf{8 . 5 E}-\mathbf{0 4}$ & $\mathbf{6 . 3 E}-\mathbf{0 4}$ & & \\
B504C_143 & $\mathbf{8 . 0 E}-\mathbf{0 7}$ & $\mathbf{7 . 3 E}-\mathbf{0 5}$ & $\mathbf{6 . 5 E}-\mathbf{0 4}$ & $\mathbf{1 . 3 E}-\mathbf{0 4}$ & $3.6 \mathrm{E}-01$ & \\
B504C_163 & $\mathbf{3 . 9 E}-\mathbf{0 8}$ & $\mathbf{2 . 1 E}-\mathbf{0 5}$ & $\mathbf{1 . 4 E}-\mathbf{0 4}$ & $\mathbf{3 . 8 E}-\mathbf{0 5}$ & $8.5 \mathrm{E}-01$ & $3.6 \mathrm{E}-01$ \\
\hline & & & & & & \\
& & & & & & \\
& & & & & \\
\end{tabular}

FTIR data received from different laboratories, working with different equipment. Thus, the findings from this study may not represent the most sensitive method of analyzing FTIR spectra for bituminous binders, but the most reproducible of all considered methods. After improving the reproducibility, the impact of shortterm ageing temperature on oxidative uptake during short- and long-term ageing was investigated. Oxidative uptake is assessed using changes in the carbonyl $(\mathrm{C}=\mathrm{O})$ and sulfoxide $(\mathrm{S}=\mathrm{O})$ bands.

A first visual inspection of spectra derived from the participants showed that all spectra exhibit similar absorption bands, however the baseline absorbance varied greatly between the laboratories. Thus, to improve the reproducibility of derived carbonyl and sulfoxide indices, two different baseline correction methods were considered. In addition, two approaches for index calculation were used: integration using the absolute baseline and a tangential baseline, respectively. The results of this analysis showed that a baseline correction that sets the absorbance spectra at the upper wavenumber limit of the carbonyl band $\left(1753 \mathrm{~cm}^{-1}\right)$ to zero $\left(\mathrm{BLC}_{\mathrm{uWN}-\mathrm{ICO}}\right)$ in conjunction with integration using the absolute baseline leads to lowest coefficients of variations (CV) (best reproducibility) for all considered samples. This approach leads to a decrease of the CV from 60 to $100 \%$ (no baseline correction) to around $20 \%$. Tangential integration resulted in worse reproducibility for both, the carbonyl and sulfoxide indices. 
Table 5 Results of t-test for $\mathrm{ISO}_{\text {base }}$ from $\mathrm{BLC}_{\mathrm{uWN}}$ ICO for all binder samples (highlighted are test values below a significance level alpha of 0.05)

\begin{tabular}{|c|c|c|c|c|c|c|}
\hline ISO_base & B501A & B501B_123 & B501B_143 & B501B_163 & B501C_123 & B501C_143 \\
\hline B501B_123 & $3.2 \mathrm{E}-01$ & & & & & \\
\hline B501B_143 & $8.7 \mathrm{E}-01$ & $3.4 \mathrm{E}-01$ & & & & \\
\hline B501B_163 & $8.8 \mathrm{E}-01$ & $2.4 \mathrm{E}-01$ & $9.6 \mathrm{E}-01$ & & & \\
\hline B501C_123 & $7.4 \mathrm{E}-01$ & $1.6 \mathrm{E}-01$ & $9.4 \mathrm{E}-01$ & $8.6 \mathrm{E}-01$ & & \\
\hline B501C_143 & $8.5 \mathrm{E}-01$ & $2.7 \mathrm{E}-01$ & $9.9 \mathrm{E}-01$ & $9.6 \mathrm{E}-01$ & $9.1 \mathrm{E}-01$ & \\
\hline B501C_163 & $1.4 \mathrm{E}-01$ & $1.9 \mathrm{E}-02$ & $3.0 \mathrm{E}-01$ & $1.6 \mathrm{E}-01$ & $1.8 \mathrm{E}-01$ & $2.3 \mathrm{E}-01$ \\
\hline ISO_base & B502A & B502B_123 & B502B_143 & B502B_163 & B502C_123 & B502C_143 \\
\hline B502B_123 & $2.8 \mathrm{E}-01$ & & & & & \\
\hline B502B_143 & $7.4 \mathrm{E}-01$ & $4.3 \mathrm{E}-01$ & & & & \\
\hline B502B_163 & $6.6 \mathrm{E}-01$ & $1.0 \mathrm{E}-01$ & $9.0 \mathrm{E}-01$ & & & \\
\hline B502C_123 & $6.9 \mathrm{E}-01$ & $8.3 \mathrm{E}-02$ & $8.7 \mathrm{E}-01$ & $9.3 \mathrm{E}-01$ & & \\
\hline B502C_143 & $5.9 \mathrm{E}-01$ & $2.0 \mathrm{E}-01$ & $9.9 \mathrm{E}-01$ & $8.2 \mathrm{E}-01$ & $7.7 \mathrm{E}-01$ & \\
\hline B502C_163 & $2.4 \mathrm{E}-01$ & $2.2 \mathrm{E}-02$ & $8.1 \mathrm{E}-01$ & $4.1 \mathrm{E}-01$ & $3.3 \mathrm{E}-01$ & $7.2 \mathrm{E}-01$ \\
\hline ISO_base & B503A & B503B_123 & B503B_143 & B503B_163 & B503C_123 & B503C_143 \\
\hline B503B_123 & $2.7 \mathrm{E}-01$ & & & & & \\
\hline B503B_143 & $8.7 \mathrm{E}-01$ & $5.1 \mathrm{E}-01$ & & & & \\
\hline B503B_163 & $7.5 \mathrm{E}-01$ & $1.6 \mathrm{E}-01$ & $6.8 \mathrm{E}-01$ & & & \\
\hline B503C_123 & $8.7 \mathrm{E}-01$ & $2.3 \mathrm{E}-01$ & $9.5 \mathrm{E}-01$ & $5.8 \mathrm{E}-01$ & & \\
\hline B503C_143 & $7.0 \mathrm{E}-01$ & $2.1 \mathrm{E}-01$ & $6.5 \mathrm{E}-01$ & $9.2 \mathrm{E}-01$ & $5.7 \mathrm{E}-01$ & \\
\hline B503C_163 & $2.1 \mathrm{E}-01$ & $3.7 E-02$ & $2.6 \mathrm{E}-01$ & $3.3 \mathrm{E}-01$ & $1.2 \mathrm{E}-01$ & $4.4 \mathrm{E}-01$ \\
\hline ISO_base & B504A & B504B_123 & B504B_143 & B504B_163 & B504C_123 & B504C_143 \\
\hline B504B_123 & $5.8 \mathrm{E}-01$ & & & & & \\
\hline B504B_143 & $8.2 \mathrm{E}-01$ & $9.0 \mathrm{E}-01$ & & & & \\
\hline B504B_163 & $5.5 \mathrm{E}-01$ & $2.5 \mathrm{E}-01$ & $5.1 \mathrm{E}-01$ & & & \\
\hline B504C_123 & $4.1 \mathrm{E}-01$ & $1.3 \mathrm{E}-01$ & $4.2 \mathrm{E}-01$ & $8.8 \mathrm{E}-01$ & & \\
\hline B504C_143 & $5.8 \mathrm{E}-01$ & $3.3 \mathrm{E}-01$ & $5.4 \mathrm{E}-01$ & $9.5 \mathrm{E}-01$ & $9.6 \mathrm{E}-01$ & \\
\hline B504C_163 & $6.6 \mathrm{E}-02$ & $1.4 E-02$ & $1.3 \mathrm{E}-01$ & $2.4 \mathrm{E}-01$ & $2.3 \mathrm{E}-01$ & $3.7 \mathrm{E}-01$ \\
\hline
\end{tabular}

Based on these findings, the second part of the study looked at the impact of short-term ageing temperature on carbonyl and sulfoxide indices using the $\mathrm{BLC}_{\mathrm{uWN}}$ ICO and absolute baseline integration. It was found that for the carbonyl index, hardly any changes could be observed due to RTFOT ageing and no significant differences between RTFOT temperatures were detected. However, significant differences were observed after long-term ageing. PAV aged samples showed a higher ICO than unaged and RTFOT aged samples. No significant impact of RTFOT temperature on PAV aged samples could be seen. Changes in the sulfoxide indices were smaller with larger scattering. Certain trends could be observed which were consistent for all four binder samples. For example, in all cases, an RTFOT at $123{ }^{\circ} \mathrm{C}$ led to a decrease of ISO relative to the unaged, whereas ISO stayed mostly the same for RTFOT at $143{ }^{\circ} \mathrm{C}$ and increased for RTFOT at $163{ }^{\circ} \mathrm{C}$. As for PAV aging, there was an increase of ISO after RTFOT at $123{ }^{\circ} \mathrm{C}$, as well as at $143{ }^{\circ} \mathrm{C}$ and $163{ }^{\circ} \mathrm{C}$. The increase is stronger with increasing RTFOT temperature. Thus, the data shows that RTFOT temperature and therefore mix production temperature has a stronger impact on the formation of sulfoxide structures than for carbonyl structures.

Based on the outcome of the study, the following conclusions and recommendations can be given: 
To ensure and improve reproducibility of results gathered from different laboratories, a strict sample handling procedure needs to be followed by all groups. This ensures that the thermal history of all samples in different laboratories is comparable.

- FTIR device, software for data collection and type of crystal (diamond or zinc selenide) used for spectroscopy does not show a systematic effect on received raw spectra. Especially the absorbance baseline varied strongly between the different laboratories, but no link between FTIR setup and this effect could be found. All but one laboratory worked with reflective spectroscopy. One laboratory used transmission spectroscopy.

- For inter-laboratory studies, any manipulation of the raw spectra should be carried out using one software and preferably by one user to prevent any impact of these parameters on the obtained indices.

- A baseline correction shifting all spectra to zero at the upper wave number limit of the carbonyl band $\left(1753 \mathrm{~cm}^{-1}\right)$ in combination with a band integration using the absolute baseline improved the reproducibility of the carbonyl index strongly and left the sulfoxide index unaffected. Thus, for interlaboratory studies, it is recommended to work using this approach to make data from different laboratories comparable. However, this method may not be the most sensitive method in terms of detecting changes due to oxidative ageing or impacts of ageing conditions, like the temperature. An investigation including repeatability and sensitivity of FTIR spectral analysis can be found in [44].

- Regarding impact of short-term ageing temperature on oxidative changes in short- and long-term aged samples, the FTIR approach used for this study could not show statistically significant impact of RTFOT temperature on short- and long-term aged binders. This is true for the carbonyl and sulfoxide indices. Significant differences can be observed between unaged or RTFOT aged samples and PAV aged samples in terms of Carbonyl Index, but not in terms of Sulfoxide Index.

- The short-term ageing temperatures shows certain patterns for all four considered samples in the sulfoxide bands. RTFOT at $123{ }^{\circ} \mathrm{C}$ leads to a decrease, whereas ISO stays mostly the same at
RTFOT at $143{ }^{\circ} \mathrm{C}$, and increases for RTFOT at $163{ }^{\circ} \mathrm{C}$. As for PAV, there is an increase in the average values after RTFOT regardless of the temperature, but the increase is not statistically significant and is well within the variability of the results. The increase is somewhat stronger with increasing RTFOT temperature.

- The scatter in the results of both FTIR indices is very significant and the results of unaged and RTFOT for all temperatures almost always overlap. This is a concern as it is known that mechanical properties are highly affected by the RTFOT aging temperature. It is also of concern that for the Sulfoxide Index the results show high scatter and similar ranges for all aging conditions including the PAV aging.

Acknowledgements Open access funding provided by TU Wien (TUW). The authors would like to express their gratitude to Zhanping You, Jeroen Besamusca and Francisco Jose Barcelo Martinez for taking part in the round robin test and providing data for this study. In addition, the authors would like to acknowledge the financial support of to the Max Kade Foundation for funding part of this study.

\section{Compliance with ethical standards}

Conflict of interest The authors state that no conflicts of interest exist.

Open Access This article is distributed under the terms of the Creative Commons Attribution 4.0 International License (http:// creativecommons.org/licenses/by/4.0/), which permits unrestricted use, distribution, and reproduction in any medium, provided you give appropriate credit to the original author(s) and the source, provide a link to the Creative Commons license, and indicate if changes were made.

\section{References}

1. Palade LI, Attane P, Camaro S (2000) Linear viscoelastic behavior of asphalt and asphalt based mastic. Rheol Acta 39(2):180-190. https://doi.org/10.1007/s003970050018

2. Garcia-Morales M, Partal P, Navarro FJ, Martinez-Boza F, Gallegos C (2004) Linear viscoelasticity of recycled EVAmodified bitumens. Energ Fuel 18(2):357-364. https://doi. org/10.1021/ef034032u

3. Costanzi M, Cebon D (2015) Generalized phenomenological model for the viscoelasticity of bitumen. J Eng Mech. https://doi.org/10.1061/(ASCE)EM.1943-7889.0000835

4. Hofko B, Handle F, Eberhardsteiner L, Hospodka M, Blab R, Fuessl J, Grothe H (2015) Alternative approach toward aging of bitumen and asphalt mixes. In: TRB 94th annual meeting compendium of papers: 15 
5. Eberhardsteiner L, Füssl J, Hofko B, Blab R, Grothe H, Handle F, Hospodka M (2014) Towards a microstructural model of bitumen aging behavior. Int J Pavement Eng. https://doi.org/10.1080/10298436.2014.993204

6. Romberg JW, Traxler RN (1947) Rheology of asphalt. J Coll Sci Imp U Tok 2(1):33-47. https://doi.org/10.1016/ 0095-8522(47)90008-1

7. Brodnyan JG, Gaskins FH, Philippoff W, Thelen E (1960) The rheology of asphalt. 3. Dynamic mechanical properties of asphalt. Trans Soc Rheol 4:279-296

8. Kim HS, Lee SJ, Amirkhanian S (2010) Rheology investigation of crumb rubber modified asphalt binders. KSCE J Civ Eng 14(6):839-843. https://doi.org/10.1007/s12205010-1020-9

9. Merusi F, Giuliani F (2011) Rheological characterization of wax-modified asphalt binders at high service temperatures. Mater Struct 44(10):1809-1820. https://doi.org/10.1617/ s11527-011-9739-4

10. Naskar M, Reddy KS, Chaki TK, Divya MK, Deshpande AP (2013) Effect of ageing on different modified bituminous binders: comparison between RTFOT and radiation ageing. Mater Struct 46(7):1227-1241. https://doi.org/10.1617/ s11527-012-9966-3

11. Asgharzadeh SM, Tabatabaee N, Naderi K, Partl MN (2015) Evaluation of rheological master curve models for bituminous binders. Mater Struct 48(1-2):393-406. https://doi. org/10.1617/s11527-013-0191-5

12. Roman C, Garcia-Morales M (2017) Linear rheology of bituminous mastics modified with various polyolefins: a comparative study with their source binders. Mater Struct. https://doi.org/10.1617/s11527-016-0953-y

13. Porot L, Eduard P (2016) Addressing asphalt binder aging through the viscous to elastic transition. In: Proceedings of the ISAP symposium 2016, Jackson Hole

14. Chen JS, Huang LS (2000) Developing an aging model to evaluate engineering properties of asphalt paving binders. Mater Struct 33(233):559-565. https://doi.org/10.1007/ Bf02480536

15. Di Benedetto H, de La Roche C, Baaj H, Pronk A, Lundstrom R (2004) Fatigue of bituminous mixtures. Mater Struct 37(267):202-216

16. Dai QL, You ZP (2008) Micromechanical finite element framework for predicting viscoelastic properties of asphalt mixtures. Mater Struct 41(6):1025-1037. https://doi.org/10. 1617/s11527-007-9303-4

17. Delgadillo R, Bahia HU, Lakes R (2012) A nonlinear constitutive relationship for asphalt binders. Mater Struct 45(3):457-473. https://doi.org/10.1617/s11527-011-9777-y

18. Eberhardsteiner L, Füssl J, Hofko B, Blab R, Grothe H, Handle F, Hospodka M (2014) Influence of asphaltene content on bitumen behavior-experimental investigation and micromechanical modeling. Mater Struct. https://doi. org/10.1617/s11527-014-0383-7

19. Das PK, Balieu R, Kringos N, Birgisson B (2015) On the oxidative ageing mechanism and its effect on asphalt mixtures morphology. Mater Struct 48(10):3113-3127. https:// doi.org/10.1617/s11527-014-0385-5

20. Perraton D, Di Benedetto H, Sauzeat C, Hofko B, Graziani A, Nguyen QT, Pouget S, Poulikakos LD, Tapsoba N, Grenfell J (2016) 3Dim experimental investigation of linear viscoelastic properties of bituminous mixtures. Mater Struct
49(11):4813-4829. https://doi.org/10.1617/s11527-0160827-3

21. Glotova NA, Gorshkov VS, Kats BI, Shapiro TM, Yureva GN (1980) Changes in rheological properties and chemicalcomposition of asphalts upon aging. Chem Tech Fuels Oil 16(3-4):278-280. https://doi.org/10.1007/bf00729932

22. Ali MF, Siddiqui MN (2001) Changes in asphalt chemistry and durability during oxidation and polymer modification. Petrol Sci Technol 19(9-10):1229-1249. https://doi.org/10. 1081/Lft-100108305

23. Gawel I, Baginska K (2004) Effect of chemical nature on the susceptibility of asphalt to aging. Petrol Sci Technol 22(9-10):1261-1271. https://doi.org/10.1081/Lft120034219

24. Xu GJ, Wang H (2016) Study of cohesion and adhesion properties of asphalt concrete with molecular dynamics simulation. Comput Mater Sci 112:161-169. https://doi.org/ 10.1016/j.commatsci.2015.10.024

25. Kumbargeri YS, Biligiri KP (2016) Rational performance indicators to evaluate asphalt materials' aging characteristics. J Mater Civ Eng. https://doi.org/10.1061/(Asce)Mt. 1943-5533.0001681

26. Poulikakos LD, dos Santos S, Bueno M, Kuentzel S, Hugener M, Partl MN (2014) Influence of short and long term aging on chemical, microstructural and macro-mechanical properties of recycled asphalt mixtures. Constr Build Mater 51:414-423. https://doi.org/10.1016/j. conbuildmat.2013.11.004

27. Mills-Beale J, You ZP, Fini E, Zada B, Lee CH, Yap YK (2014) Aging influence on rheology properties of petroleum-based asphalt modified with biobinder. J Mater Civ Eng 26(2):358-366. https://doi.org/10.1061/(Asce)Mt. 1943-5533.0000712

28. Yao H, Dai QL, You ZP (2015) Fourier Transform Infrared Spectroscopy characterization of aging-related properties of original and nano-modified asphalt binders. Constr Build Mater 101:1078-1087. https://doi.org/10.1016/j. conbuildmat.2015.10.085

29. Taylor R, Harrigan E, Aurilio V, Chollar BH (1998) Rheological \& structural analysis of recovered asphalt binders from the FHWA ALF rutting \& fatigue experiments, part III FTIR spectral analysis. Abstr Pap Am Chem S 216:U847

30. Mothe MG, Leite LFM, Mothe CG (2008) Thermal characterization of asphalt mixtures by TG/DTG, DTA and FTIR. J Therm Anal Calorim 93(1):105-109. https://doi. org/10.1007/s10973-007-8807-Z

31. Zhang F, Yu JY, Han J (2011) Effects of thermal oxidative ageing on dynamic viscosity, TG/DTG, DTA and FTIR of SBS- and SBS/sulfur-modified asphalts. Constr Build Mater 25(1):129-137. https://doi.org/10.1016/j.conbuildmat. 2010.06.048

32. Cao XJ, Lei YB, Wang W (2011) Study on thermal oxidation of asphalt fractions by in-situ FTIR analysis. Mater Sci Eng Appl Pts 1-3(160-162):330-335. https://doi.org/10. 4028/www.scientific.net/AMR.160-162.330

33. Bowers BF, Huang BS, Shu X, Miller BC (2014) Investigation of reclaimed asphalt pavement blending efficiency through GPC and FTIR. Constr Build Mater 50:517-523. https://doi.org/10.1016/j.conbuildmat.2013.10.003

34. Marsac P, Pierard N, Porot L, Van den Bergh W, Grenfell J, Mouillet V, Pouget S, Besamusca J, Farcas F, Gabet T, 
Hugener M (2014) Potential and limits of FTIR methods for reclaimed asphalt characterisation. Mater Struct 47(8):1273-1286. https://doi.org/10.1617/s11527-0140248-0

35. Yang X, You ZP, Mills-Beale J (2015) Asphalt binders blended with a high percentage of biobinders: aging mechanism using FTIR and rheology. J Mater Civ Eng. https://doi.org/10.1061/(Asce)Mt.1943-5533.0001117

36. Nivitha MR, Prasad E, Krishnan JM (2016) Ageing in modified bitumen using FTIR spectroscopy. Int J Pavement Eng 17(7):565-577. https://doi.org/10.1080/10298436. 2015.1007230

37. Feng ZG, Wang SJ, Bian HJ, Guo QL, Li XJ (2016) FTIR and rheology analysis of aging on different ultraviolet absorber modified bitumens. Constr Build Mater 115:48-53. https://doi.org/10.1016/j.conbuildmat.2016.04. 040

38. Feng ZG, Bian HJ, Li XJ, Yu JY (2016) FTIR analysis of UV aging on bitumen and its fractions. Mater Struct 49(4):1381-1389. https://doi.org/10.1617/s11527-0150583-9

39. Partl M, Bahia H, Canestrari F, De La Roche C, Di Benedetto H, Piber H, Sybilski DZ (2013) Advances in interlaboratory testing and evaluation of bituminous materials. Springer, Dordrecht

40. Smith BC (2011) Fundamentals of Fourier transform infrared spectroscopy. CRC Press, Boca Raton, FL

41. Petersen JC, Glaser R (2011) Asphalt oxidation mechanisms and the role of oxidation products on age hardening revisited. Road Mater Pavement 12(4):795-819. https://doi.org/ 10.3166/Rmpd.12.795-819

42. Liu M, Ferry MA, Davison RR, Glover CJ, Bullin JA (1998) Oxygen uptake as correlated to carbonyl growth in aged asphalts and asphalt Corbett fractions. Ind Eng Chem Res 37(12):4669-4674. https://doi.org/10.1021/ie980450o

43. Dony A, Zyian L, Drouadaine I, Pouget S, Faucon-Dumont S, Simard D, Mouillet V, Gabet T, Boulange L, Nicolai A, Guiet C (2016) MURE National Project: FTIR spectroscopy study to assess ageing of asphalt mixtures. In: Proceedings of the E\&E congress 2016, Prague
44. Hofko B, Alavi MZ, Grothe H, Jones D, Harvey J (2017) Repeatability and sensitivity of FTIR ATR spectral analysis methods for bituminous binders. Mater Struct 50:187. https://doi.org/10.1617/s11527-017-1059-x

45. CEN (2009) EN 12591: Bitumen and bituminous binders. Specifications for paving grade bitumens. Brussels, Belgium

46. CEN (2007) EN 12607-1: Bitumen and bituminous binders-determination of the resistance to hardening under the influence of heat and air-part 1: RTFOT method. Brussels

47. CEN (2012) EN 14769: Bitumen and bituminous bindersaccelerated long-term ageing conditioning by a pressure ageing vessel (PAV). Brussels

48. CEN (2016) EN 1426: Bitumen and bituminous bindersdetermination of needle penetration. Brussels

49. CEN (2015) EN 1427: Bitumen and bituminous bindersdetermination of the softening point-ring and ball method. Brussels

50. AASHTO (2010) AASHTO M 320-10: standard specification for performance-graded asphalt binder. American Association of State and Highway Transportation Officials, Washington, DC

51. Lamontagne J, Dumas P, Mouillet V, Kister J (2001) Comparison by Fourier transform infrared (FTIR) spectroscopy of different ageing techniques: application to road bitumens. Fuel 80(4):483-488. https://doi.org/10.1016/ S0016-2361(00)00121-6

52. Petersen JC (1975) Quantitative method using differential infrared spectrometry for determination of compound types absorbing in carbonyl region in asphalts. Anal Chem 47(1):112-117

53. Liu HY, Hao PW, Wang HN, Adhikair S (2014) Effects of physio-chemical factors on asphalt aging behavior. J Mater Civ Eng 26(1), pp. 190-197. https://doi.org/10.1061/ (ASCE)MT.1943-5533.0000786

54. Morrison J (2009) Statistics for engineers: an introduction. Wiley, Hoboken, NJ 